\title{
The Effects of habitat fragmentation on the distribution of primates in the kimbi-fungom National Park, North West Region, Cameroon
}

\begin{abstract}
Anthropogenic disturbance is known to affect the diversity and abundance of primates in the world. Many studies on primates in Cameroon have focused on forest ecosystems, with little knowledge on primate species in the degraded woodland and grasslands which inhabit a great number of primates. This study investigates the relationship between primate distribution and habitat parameters in the heavily human occupied landscape of Kimbi Fungom National Park (KFNP). Primate data were obtained through the use of line transects, and interview. A total of twenty 3-kilometre transects were laid in the national park area. In addition, assessment of ecological factors such as forest fragment size, habitat types, and habitat structure (canopy height) was carried out. Data analysis was run using the Statistical Package for Social Sciences (SPSS). Ecological variables were analysis by chi-square $\left(\chi^{2}\right)$, to assess the impact of habitat parameters on primate's diversity. The study observed 6 primate species in the national park area; chimpanzees (Pan troglodytes ellioti), Olive baboons (Papio anubis), Patas monkeys (Erythrocebus patas), Mona monkeys (Cercopithecus mona), Putty-nosed monkey (Cercopithecus nictitans) and Vervet monkeys (Chlorocebus pygerythrus) with low densities. Baboons were the most numerous species while putty-nosed monkey was the most frequently encountered. However, three ecological factors were found to significantly affect the distribution of primates; habitat types $\left(\chi^{2}=3.069, \mathrm{df}=1, \mathrm{p}=.048\right)$, habitat structure $\left(\chi^{2}=4.992, \mathrm{df}=1 \mathrm{p}=0.025\right)$ and landscape $\left(\chi^{2}=8.225, \mathrm{df}=1, \mathrm{p}=.004\right)$. Detections of patas monkeys and baboons were higher in areas with low forest strata, having mainly grassland and woody savanna ecosystem. This study recommends the need for sustainable agricultural practices, control grazing, selective logging and continuous education of local population on primate conservation.
\end{abstract}

Keywords: anthropogenic disturbance, primates, woodland, ecological factors, forest fragments
Volume 4 Issue 2 - 2019

\author{
Melle Ekane Maurice, Nkwatoh Athanasius \\ Fuashi,Amos Fang Zeh \\ Department of Environmental Science, University of Buea, \\ Cameroon
}

\begin{abstract}
Correspondence: Melle Ekane Maurice, Department of Environmental Science, University of Buea, P.O. Box 63, Buea, Southwest Region, Cameroon, Tel +237675393156,
\end{abstract} Emailmelleekane@gmail.com

Received: February 13, 2019 | Published: April 03, 2019

\section{Introduction}

Habitat characteristics and human actions are the major leading forces of primate distributions in the world. This effect is stemmed from two main factors; structural variables of the habitat or habitat quality and indirect and direct anthropogenic impacts. ${ }^{1,2}$ Peres $^{3}$ and Pinto et al., ${ }^{4}$ observed that on a larger scale, the diversity and density of primates in natural forests, both in the Neotropics and elsewhere depend much on primary forest productivity, precipitation and climatic seasonality. Locally, different primate species occupy different forest microhabitats, preferring different forest strata or forest types of different structure such as liana thickets. ${ }^{5,6}$ Vegetation is thus an important factor for wildlife survival, providing food, cover and protection for wild animal species. ${ }^{7}$ Forests alone cover 4.03 billion hectares globally, approximately $30 \%$ of Earth's total land area. ${ }^{8}$ These Forests harbor the majority of species on Earth which provide valuable ecosystem goods and services to humanity, including food, fiber, timber, medicine, clean water, aesthetic and spiritual values, and climate moderation and are the major habitats for primates. ${ }^{9}$

The greatest diversity of primates in the world is found in the Amazon basin. ${ }^{10}$ Increasing human activity in and around the Amazon basin threatens the future and persistence of the Amazonian mammals and regions of this biome are still pristine and offer an opportunity to study community structure. ${ }^{11,12}$ Africa equally harbours high primate diversity with at least 64 recognized species; fifteen prosimians, 46 monkeys and three apes representing approximately $30 \%$ of extant primate species. ${ }^{13}$ In a study conducted by Cowlishaw \& Dunbar, ${ }^{14}$ it was observed that among fifteen countries worldwide scoring highest for primate species richness, nine are in Africa; including Democratic Republic of Congo (DRC), Cameroon, Nigeria, Peoples Republic of Congo, Equatorial Guinea and Central African Republic. ${ }^{14}$ Cameroon is part of the Congo Basin and harbours a wide range of biological resources. It is the fourth most biological diversified country in Africa after the Democratic Republic of Congo, Tanzania and Madagascar. ${ }^{15}$

The distribution of primates in it natural habitats in recent times have been affected by habitat fragmentation and loss from the growing human population. Habitat fragmentation through deforestation is the main cause of wildlife habitat shrinkage and change and it is one of the major threats most of the world protected areas are facing today. ${ }^{16}$ Changes in land cover through deforestation represent serious threats to ecosystem sustainability especially when naturally vegetated forms give way to human use. Agriculture, settlement, and timber exploitation are well documented forest ecosystem fragmentors. These forest degraders are also known to facilitate the invasion of natural forest by exotic species and the speed up natural change processes. ${ }^{17}$ Presently, accelerated deforestation is causing rapid loss and fragmentation of primary habitats for primates. ${ }^{18}$ Tropical forest loss and fragmentation have been advocated as the main causes of flora and fauna population declines/species extinction in the tropics. ${ }^{19}$ Fragmented habitats as demonstrated by Adler \& Nuernberger ${ }^{20}$ have negatively affected species moving between empty patches for recolonisation which results in reduced local population sizes and species extinction. This may lead to high rate of population declines and faunal extinction in the tropics. ${ }^{19}$ Harcourt and Doherty, ${ }^{21}$ noted 
that primate richness decreased with fragment size but in some isolated relatively small forest patches primate densities have been found to increase, possibly owing to the absence of main predators such as large cats and birds of prey. ${ }^{22}$ The persistence of primates in small fragmented forests depends on their ability to cope with changes. ${ }^{23}$ Studies suggest that some primates can persist in fragmented forests as a result of increasing land use based on their ability to feed on available food species and items, ${ }^{23,24}$ adjust their activity pattern to the new modified habitats ${ }^{24,25}$ and to use smaller home ranges. ${ }^{26}$ Based on the threat posed by increasing habitat fragmentation, there is high concern towards the conservation of primates. ${ }^{19}$ The most vital steps in designing effective conservation management strategies are the assessment of population parameters such as size, density, and distribution of a species across the landscape. These are important baseline data which can be utilized to assess conservation status and to measure success of conservation efforts over time. Population size and density are important for long $\square$ term monitoring, and the distribution of individuals and their use of space are informative in targeting key areas of protection. ${ }^{27}$

In Cameroon, primate studies have been carried out, but this has been limited to the forest regions. There are little records of primates in the study area. This reason motivated this survey to identify the different primates found in the park and to ascertain the population density in this rich ecoregion. It is for this reason that this study was undertaken in the Kimbi-Fungom National Park found in the Western Highland of Cameroon with diverse habitats which have been identified to host a great number of primates. Knowledge of the biodiversity of the Kimbi Fungom National park is limited and scattered. Two important criteria in the evaluation of conservation areas are species richness and the conservation status of its taxa. ${ }^{28}$
To be able to set effective conservation measures for Kimbi Fungom National Park (KFNP), it is therefore essential to assess its biodiversity, collect natural history data, and evaluate the relative abundance of the fauna in this heavily occupied landscape.

\section{Materials and methods}

\section{Description of the study area}

Kimbi-Fungom National Park (KFNP) is located between latitude 6.5-6.9 $\mathrm{N}$ and longitude $9.8-10.5^{\circ} \mathrm{E}$ in the Northwest Region of Cameroon and covers a total land surface area of 95,380 hectares (Figure 1). This national park is situated within three administrative divisions in the Northwest Region of Cameroon; Menchum, Boyo and Dongo Mantung. ${ }^{29}$ The region experiences two seasons, a long rainy season from mid March to mid November, and a short dry season from mid November to mid March. The wettest months are July, August and September and the driest months being January and February. The national park drainage system includes Kimbi, Katsina Al, and Kendassamen rivers. The soil types in this area include acrisols, andosols (Black soils of volcanic landscapes), and ferrasols. ${ }^{30}$ The vegetation is principally lowland tropical rainforest at the Fungom low altitude area of the national park, which is progressively transformed into a savanna landscape towards its northern region. The national park also harbors many wildlife species; primates, ungulates, carnivores, a host of rodents, reptiles and amphibians. Endangered species such as Chimpanzee (Pan troglodytes ellioti) and pangolin (Smutsia gigantea) are found in the park. Other primates include Mona monkeys (Cercopithecus mona), Putty-nosed monkeys (cercopithecus nictitans) and baboons (Papio anubis and P. cynocephalus).

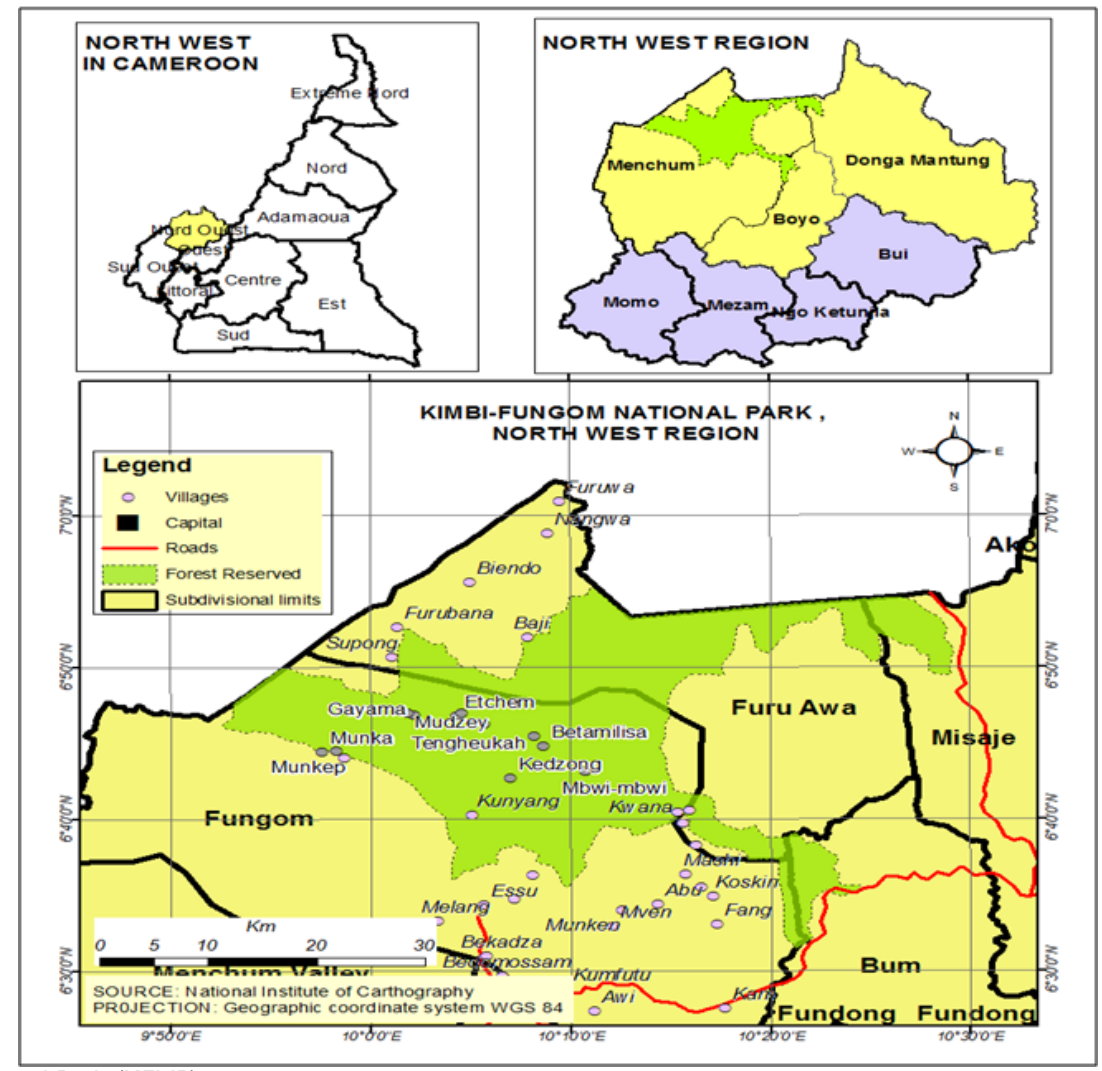

Figure I Kimbi Fungom National Park (KFNP) map. 


\section{Research data collection}

After understanding the vegetation of the national park and the orientation of the topography, the park was divided into 20 research blocks. This was to avoid bias in forest fragment selection and data collection on primates since the national park is made up of different vegetation types affected by human activities. The line transects technique as described by Buckland et al. ${ }^{31}$ was employed. The line transect survey method has been used by several researchers on their study of mammals, especially primates in Africa due to the nature of mammalian species and rugged terrain of most study areas in the continent. ${ }^{32}$ In each block a 3-kilometre-transect was established in selected forest fragments taking into consideration the landscape configuration. A total of twenty 3-line transects were established in the national park with the aid of GPS. Since the park is made up of different vegetation types, we made sure that the starting points of all transects were from the forested area. Most of these forest fragments were surrounded by farm and grazing land, ranging from 2.2 hectares to 76 hectares, fragmented from 1982 to 2018 . Line transects have been the main method used to survey diurnal primates. ${ }^{31}$ About 2 hours were used to walk on each transect, ${ }^{33}$ looking ahead and sideways to detect animals, and occasionally using binoculars to determine primate group sizes. Each transect was walked by three observers, within the range of $25 \mathrm{~m}$ on both sides of the central line. In small forest fragments (isolated fragment from human actions and gallery forests) and dense woody savanna, we focused on concentrated searches once informed about the presence of primates. We followed pre-existing human trails and maintained a straight line so as to have little or no effects on the perpendicular distance estimation. Intense searches were made in all fragments where primates had been observed before or were noted to have been endemic. Also, during this transect-walk, all animals sighted, vocalizations, signs (dung, resting places, foot prints, carcasses, tracks and food remains) were recorded. In addition, we recorded perpendicular distance data by categorizing them into 13 distance intervals; $0-10 \mathrm{~m}, 11-20 \mathrm{~m}, 21-30 \mathrm{~m}, 31-40 \mathrm{~m}$, $41-50 \mathrm{~m}, 51-60 \mathrm{~m}, 61-70 \mathrm{~m}, 71-80 \mathrm{~m}, 81-90 \mathrm{~m}, 91-100 \mathrm{~m}, 101-150 \mathrm{~m}$, $151-200 \mathrm{~m}$, and $201-350 \mathrm{~m}$. To ensure that perpendicular distances were estimated accurately, observers were trained on evaluating distances by eye prior to the onset of the study (Leca et al. 2013). The tree height was categorized into 11 different categories; $1-3 \mathrm{~m}$, 4-6m,7-9m, 10-12m, 13-15m,16-18m, 19-21m, 22-24m, 25-27m, $28-30 \mathrm{~m}$. A digital camera was used to take photographs of primates and other wildlife species as well as signs of anthropogenic activities while a binocular $(10 \mathrm{x} 45)$ was used to observe animals away from the transect.

\section{Data analysis}

The perpendicular distances measured were used to estimate a detection function (that is, the probability that a primate is detected, as a decreasing function of its distance from the line). This permitted the calculation of primate density (groups of primates) in the study area. ${ }^{34}$ In order to provide estimates of primate density and abundance in the national park, the computer software program distance 7.2 was used. ${ }^{34}$ The samples of animal encounters reached the size required by this program, since primate observations (51) reached the recommended observation number needed (30-40) with more accuracy from 60 $80 . .^{31,34}$ To estimate the mean group size, we averaged the number of individuals detected (that is seen not heard) during the encounters of different groups. Individual primate densities were calculated using a combination of transects surveys and concentrated (total count) in areas where groups had been seen. The encounter rate $(\mathrm{n} / \mathrm{L})$ was defined as the number of groups detected per unit length of transect, that is per kilometer walked. After testing different detection function models, we selected the one that best fits our data set, based on wellestablished criteria. ${ }^{34}$ The effect of ecological factors on the primate distribution was examined (fragment size, habitat types, vegetation structure, landscape) and other factors contributing to primate distribution; weather, season, time spent with primates and time of the day.

\section{Results}

The results of this study revealed that some ecological factors affected the distribution of primates in the national park: habitat structure, $\chi^{2}=4.992, \mathrm{df}=1 \mathrm{P}=0.025$ (Figure 2), habitat-type $\chi^{2}=3.069$, $\mathrm{df}=1, \mathrm{P}=.048$ (Figure 3) and landscape, $\chi^{2}=8.225, \mathrm{df}=1, \mathrm{P}=.004$ (Figure 4). An observation of the following primate species was made; baboons (Papio anubis), patas monkey (Erythrocebus patas), vervet monkeys (Chlorocebus pygerythrus), white-nosed monkeys (Cercopithecus nictitans), and mona monkeys (Cercopithecus mona) within the national park. Moreso, there was an observation of 9 groups of baboons with group size ranging from 10-32 individuals, 11 groups of mona monkey with group size raging from 8-18 individuals, 13 groups of white-nosed monkeys with group size raging from 6-17, 8 groups of vervet monkeys with a group size range of 8-21individuals, 7 groups of patas monkeys with group size ranging from 7-18 individuals. There was also evidence of the presence of chimpanzee (Pan troglodytes ellioti) through their nests and vocalizations. 16 chimpanzee nests were observed in 3 locations, and 8 calls were recorded (Table 1).

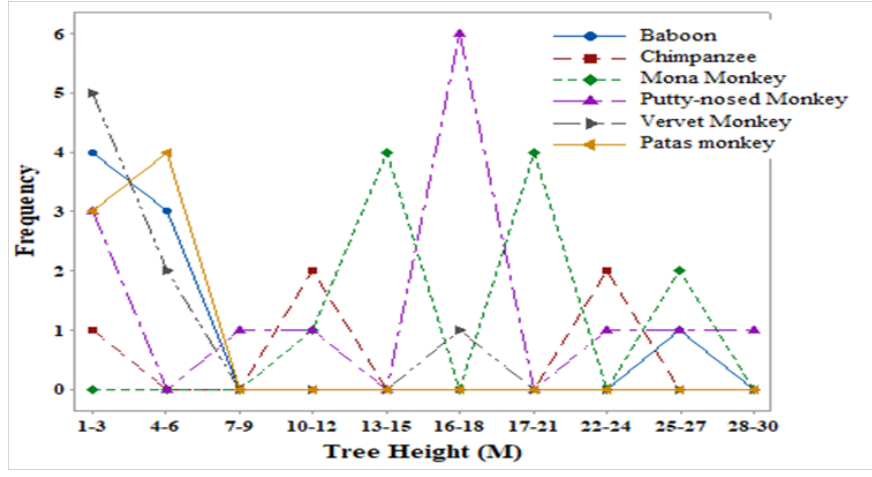

Figure 2 Distribution of primates according to habitat structure.

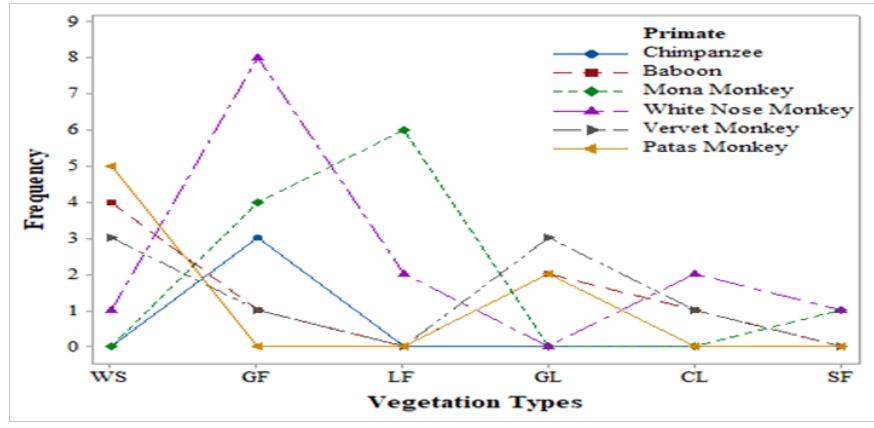

Figure 3 Distribution of primates according habitat-types.

The observations made on the height of the primate species from the ground surface revealed $17.6 \%$ for baboons, $5.9 \%$ for chimpanzees, $21.6 \%$ for mona monkeys, $25.5 \%$ for white-nosed 
monkey, $15.7 \%$ for vervet monkeys, and $13.7 \%$ for patas respectively.

This is a clear indication that these primate species are arboreal (Table

2). The chimpanzees were observed with the least arboreal life due to the body size, as compared to the quenon monkeys (mona and whitenosed monkeys) lighter in body weight. In primates the body weight is a determinant to their arboreal life.

Table I Primate Group and encounter rates

\begin{tabular}{llllll}
\hline Species & Total distance $(\mathbf{k m})$ & Group number & Group ER & Individual number & Individual ER \\
\hline Baboons & 274 & 9 & 0.03 & 170 & 0.62 \\
Chimpanzee & 274 & 3 & 0.01 & 16 & 0.06 \\
Mona monkey & 274 & 11 & 0.04 & 131 & 0.48 \\
White nose monkey & 274 & 13 & 0.05 & 142 & 0.52 \\
Velvet monkey & 274 & 8 & 0.03 & 122 & 0.45 \\
Patas monkey & 274 & 7 & 0.03 & 89 & 0.32 \\
Total & 274 & 51 & 0.19 & 670 & 2.45 \\
\hline
\end{tabular}

Table 2 Association between the arboreal height and primate species distribution

\begin{tabular}{|c|c|c|c|c|c|c|c|}
\hline \multirow{2}{*}{$\begin{array}{l}\text { Vertical } \\
\text { distance } \\
\text { range (M) }\end{array}$} & \multicolumn{6}{|l|}{ Species } & \multirow{2}{*}{ Total } \\
\hline & Baboons & Chimpanzee & Mona monkey & White nose monkey & Vervet monkey & Patas monkey & \\
\hline \multirow{2}{*}{0} & 0 & 0 & 0 & 0 & 0 & I & I \\
\hline & $0.00 \%$ & $0.00 \%$ & $0.00 \%$ & $0.00 \%$ & $0.00 \%$ & $100.00 \%$ & $100.00 \%$ \\
\hline \multirow{2}{*}{$1-3$} & 5 & 0 & 0 & 2 & 4 & 2 & 13 \\
\hline & $38.50 \%$ & $0.00 \%$ & $0.00 \%$ & $15.40 \%$ & $30.80 \%$ & $15.40 \%$ & $100.00 \%$ \\
\hline \multirow{2}{*}{$4-6$} & 3 & 0 & 0 & 0 & 3 & 4 & 10 \\
\hline & $30.00 \%$ & $0.00 \%$ & $0.00 \%$ & $0.00 \%$ & $30.00 \%$ & $40.00 \%$ & $100.00 \%$ \\
\hline \multirow{2}{*}{$10-12$} & 0 & I & 1 & I & 0 & 0 & 3 \\
\hline & $0.00 \%$ & $33.30 \%$ & $33.30 \%$ & $33.30 \%$ & $0.00 \%$ & $0.00 \%$ & $100.00 \%$ \\
\hline \multirow{2}{*}{$13-15$} & 0 & 2 & 4 & 0 & 0 & 0 & 5 \\
\hline & $0.00 \%$ & $33.3 . \%$ & $66.7 . \%$ & $0.00 \%$ & $0.00 \%$ & $0.00 \%$ & $100.00 \%$ \\
\hline \multirow{2}{*}{$16-18$} & 0 & 0 & 0 & 7 & 0 & 0 & 7 \\
\hline & $0.00 \%$ & $0.00 \%$ & $0.00 \%$ & $100.00 \%$ & $0.00 \%$ & $0.00 \%$ & $100.00 \%$ \\
\hline \multirow{2}{*}{$|9-2|$} & 0 & 0 & 5 & 0 & I & 0 & 6 \\
\hline & $0.00 \%$ & $0.00 \%$ & $83.30 \%$ & $0.00 \%$ & $16.70 \%$ & $0.00 \%$ & $100.00 \%$ \\
\hline \multirow{2}{*}{$22-24$} & 0 & 0 & 0 & I & 0 & 0 & I \\
\hline & $0.00 \%$ & $0.00 \%$ & $0.00 \%$ & $100.00 \%$ & $0.00 \%$ & $0.00 \%$ & $100.00 \%$ \\
\hline \multirow[b]{2}{*}{$25-27$} & I & 0 & 1 & I & 0 & 0 & 3 \\
\hline & $33.30 \%$ & $0.00 \%$ & $33.30 \%$ & $33.30 \%$ & $0.00 \%$ & $0.00 \%$ & $100.00 \%$ \\
\hline \multirow{2}{*}{$28-30$} & 0 & I & 0 & 2 & 0 & 0 & 2 \\
\hline & $0.00 \%$ & $0 \%$ & $0.00 \%$ & $100.00 \%$ & $0.00 \%$ & $0.00 \%$ & $100.00 \%$ \\
\hline \multirow{2}{*}{ Total } & 9 & 3 & 11 & 13 & 8 & 7 & 51 \\
\hline & $17.60 \%$ & $5.90 \%$ & $21.60 \%$ & $25.50 \%$ & $15.70 \%$ & $13.70 \%$ & $100.00 \%$ \\
\hline
\end{tabular}


The landscape was another environmental that was witnessed determining the primate troop encounters (Table 3). A total of 19 troops of primates were encountered on the gentle slope areas of the national park. This might be because of availability of food resources, easily accessible as compared to other landscape areas which were observed with primate food in some locations but with difficult access. The valleys were observed with the least number of primate troops 7 , low food availability of this area might be considered as a key contributor to the low primate troop frequency in the area.

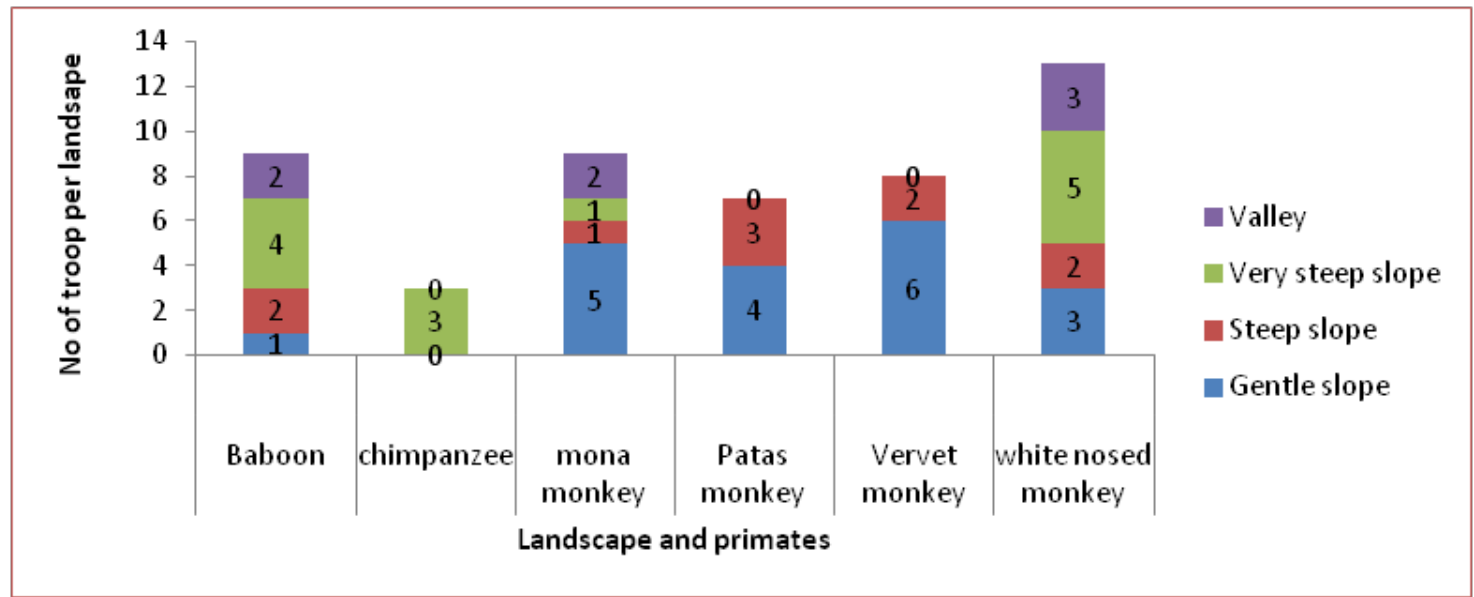

Figure 4 Distribution of primates troops on landscape.

Table 3 Association between landscape and species distribution

\begin{tabular}{|c|c|c|c|c|c|}
\hline \multirow{2}{*}{ Species } & \multicolumn{4}{|l|}{ Landscape } & \multirow{2}{*}{ Total } \\
\hline & Gentle slope & Steep slope & Very steep slope & Valley & \\
\hline \multirow{2}{*}{ Baboons } & I & 2 & 4 & 2 & 9 \\
\hline & $5.30 \%$ & $20 \%$ & $26.70 \%$ & $28.60 \%$ & $17.60 \%$ \\
\hline \multirow{2}{*}{ Chimpanzee } & 0 & 0 & 3 & 0 & 3 \\
\hline & $0.00 \%$ & $0.00 \%$ & $20 \%$ & $0.00 \%$ & $5.90 \%$ \\
\hline \multirow{2}{*}{ Mona monkey } & 5 & I & 3 & 2 & II \\
\hline & $26.30 \%$ & $10 \%$ & $20 \%$ & $28.60 \%$ & $21.60 \%$ \\
\hline \multirow{2}{*}{ White nose monkey } & 3 & 2 & 5 & 3 & 13 \\
\hline & $15.80 \%$ & $20 \%$ & $30 \%$ & $42.90 \%$ & $25.50 \%$ \\
\hline \multirow{2}{*}{ Vervet monkey } & 6 & 2 & 0 & 0 & 8 \\
\hline & $31.60 \%$ & $20 \%$ & $0.00 \%$ & $0.00 \%$ & $15.70 \%$ \\
\hline \multirow{2}{*}{ Patas monkey } & 4 & 3 & 0 & 0 & 7 \\
\hline & $21.10 \%$ & $30 \%$ & $0.00 \%$ & $0.00 \%$ & $13.70 \%$ \\
\hline \multirow{2}{*}{ Total } & 19 & 10 & 15 & 7 & 51 \\
\hline & $100.00 \%$ & $100.00 \%$ & $100.00 \%$ & $100.00 \%$ & $100.00 \%$ \\
\hline
\end{tabular}

The survey has recorded the highest primate group frequency on white-nosed monkeys $25.5 \%$ and the least on chimpanzees $5.3 \%$ (Figure 5). The primate group encounter rate might also reflect the primate species population in the national park. There is an indication that white-nosed monkey has the highest number of primates in the national park. This survey revealed that it is easier to encounter a white-nosed monkey troop that any other primate species in the national park. White-nosed monkeys have a relative smaller body size, a body morphology that can take it to cliffs or steep slopes for feeding and foraging than any other primate species. Poachers might prefer killing other primate species such as baboons with relative heavier body structure and not very arboreal that the arboreal guenon monkeys difficult to target in hunting. Moreover, targeting guenons such as white-nosed and mona monkeys during a hunting episode might be considered as a waste of energy and bullets.

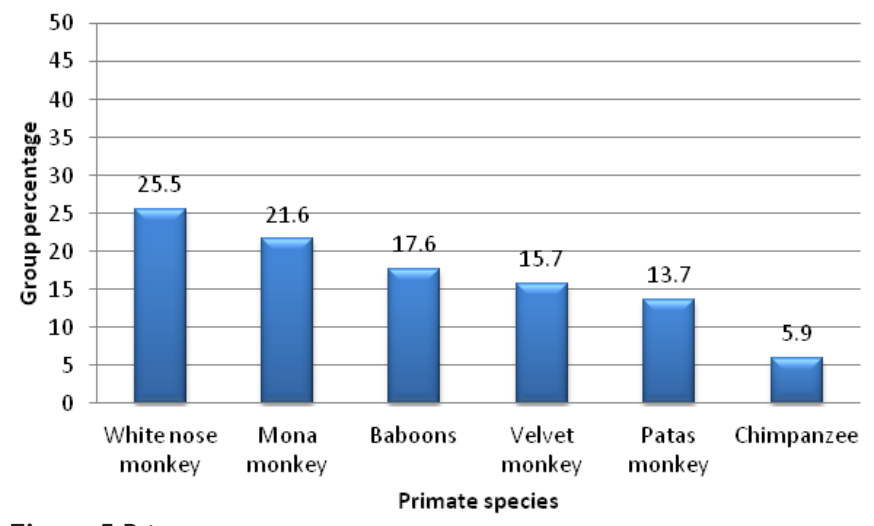

Figure 5 Primate troops encounter. 


\section{Discussion}

Understanding the causes of broad $\square$ scale gradients of species diversity remains a leading question in ecology. For many years, explanations adopted either an ecological or an evolutionary standpoint, that is, whether species diversity was subject to particular environmental determinants-as inferred from correlative modelsor to differences in diversification timing and rates, respectively. ${ }^{35}$ Growing evidence indicates, however, that the geographic gradients of species richness within biological groups are largely related to an overall tendency of species to retain ancestral niche features (i.e. niche conservatism) together with the evolutionary time necessary for each biogical group to diversify. ${ }^{36}$ These mechanisms apply to many extant clades, including those of tropical and temperate organisms ${ }^{37}$ as well as extinct lineages (Martinez $\square$ Meyer, Peterson \& Hargrove 2004) As most extant clades are tropical in origin, they have accumulated species in tropical zones more than in temperate ones, thus resulting in a negative trend of species richness towards the poles. ${ }^{36}$ In this context, since the diversification of species within a clade is largely influenced by the conditions at the origin and during the subsequent history of the clade,$^{38}$ the condition currently associated with higher levels of species richness can hint at the main environmental axis determining the distribution and diversification of that clade. In addition, contemporary conditions and events (e.g. anthropogenic changes in habitat and climate) continue to influence species diversity by removing species from some areas and adding them to others. ${ }^{39}$ As niches are generally conserved over large time $\square$ scales, species tend to have a limited ability to respond to rapid changes in environmental conditions. ${ }^{38}$ This emphasizes the relevance of identifying the environmental drivers of patterns of species richness, as they indicate the key conditions that are expected to affect species richness following ongoing environmental changes.

Chimpanzees were the least primate species encountered during the survey, only 3 chimpanzee nest sites with a total number of 16 nests were observed. This assertion was confirmed by $100 \%$ of respondents, as old farmers who entered the park by the late 1970 s recounted that chimpanzees were frequently seen as well as their calls heard on a daily bases. Similar results of low density of the NigeriaCameroon chimpanzee were reported by Mvo \& $\mathrm{Tsi}^{40}$ in Menchum South. The Regional Action Plan Project for the Conservation of Nigeria-Cameroon Chimpanzee recorded the presence of chimpanzee in the Fungom forest Reserve. Low density of the Nigerian-Cameroon chimpanzee has also been reported in the idanre forest cluster and Ise Forest Reserve. ${ }^{41}$ All nests were located in high altitude steep rocky gallery forest at Gayama, Etchem and Mbwi-Mbwi in the Fungom forests of the park. ${ }^{42}$ Similar observations were made in the Oban Hills on the Nigeria-Cameroon chimpanzee. ${ }^{43}$ All 13 arboreal nests encountered were found in the rocky forest habitat at two different sites. This made us conclude that the dwindling of chimpanzee population is not linked to food shortages but habitat fragmentation (human activity) and hunting pressure. However, the presence of human activities might have seriously affected the chimpanzee population distribution and their low density. Chimpanzees are now resorted to steep rocky gallery forest where they are thought to be free from hunters. Rachel ${ }^{41}$ also observed that the Nigeria-Cameroon chimpanzees mostly inhabit the gallery forest patches along an area characterized by boulders vegetation. All chimpanzees are endangered species and the Nigerian-Cameroon chimpanzee (Pan troglodytes ellioti) is considered the most endangered of all currently known chimpanzee subspecies as well as being the most range-restricted. ${ }^{44}$
Baboons are believed to be the adapted primate species in the national park. We detected the presence of the olive baboons in the park with a density of $1.55 / \mathrm{km}^{2}$ and encounter rate of $0.62 / \mathrm{km}$. Their observation in the savanna, woodland (both lowland and highland savanna) and gallery forests confirms their high population as well. The high level of adaptability of baboons in the degraded landscape of the national park might be due to their ability to crop-raid. ${ }^{45}$ For instance, the olive baboon in grassland goes about finding food differently from those in the forest. ${ }^{46}$ Baboon distribution and abundance across the landscape can be explained primarily by the distribution of the most lucrative foraging sites. Human-modified habitats offer abundant, accessible and good food sources that baboons favour over the low quality forage of local indigenous vegetation. ${ }^{47}$ The olive baboon eats leaves, grass, roots, bark, flowers, fruit, lichens, tubers, seeds, mushrooms, corms, and rhizomes. ${ }^{48}$ These foods are relatively abundant in the park thus, enough to sustain a high population of baboons. The baboon forages on all levels of an environment, above and beneath the ground and in the canopy of forests. ${ }^{45}$

We encountered at least 82 patas monkeys living in 8 groups on the savanna area of the national park (Kimbi grassland and the Fungom woody savanna) with population sizes ranging from $8-22$. The density of patas was $0.81 / \mathrm{km}^{2}$ while encounter rate was $0.32 \mathrm{~km}$ walked. This estimate was based on many groups of patas monkeys encountered. They mainly utilized the gentle slopes during the dry season where seasonal streams were found and were mainly detected on grazing land (woody and grassland savanna) and upland gallery forests. Patas were noted to have a variety of food from the vegetation, though they mainly utilized the grazing land which was degraded. Despite the fact that patas monkeys mainly utilized the degraded woodland of the park (grazing land), they do not appear to suffer from the presence of cattle because patas monkeys do feed on the food with cattle and they occur naturally at densities too low to compete for water with livestock. ${ }^{49}$ Most often patas monkeys in the park retreats to lowland woodland in the dry season or roam around the upland gallery forest with seasonal streams where they can obtain water. They hardly escape dry conditions because patas monkeys have adapted to survive in drier habitats provided they have food. ${ }^{49}$ Most respondents were of the opinion that patas monkeys dominate the Esu woodland and are thought to expand more due to the primate protection tradition of these people. According to them, the national park harbors very few patas monkeys as compared to their population in the woodlands area at the periphery of the national park.

Vervet monkeys were detected in the grassland, woody savanna and the gallery forests with density of $1.72 / \mathrm{km}^{2}$ and encounter rate of 0.45 . Vervets were seen to be well adapted to woody habitats and utilized mainly the gentle slopes of the national park in lower vegetation structure areas. Out of the 8 groups of vervet monkeys encountered in the national park, 6 were seen in gentle slopes. They spent a large portion of their moving time on the ground making them semi-terrestrial. ${ }^{50}$ They were always found relatively close to streams and are associated with the riverine or gallery forest vegetation, similar to the observation made by a number of researchers. ${ }^{50}$ In Eritrean vervet home-range, proportions of forested and woody areas were significantly higher than expected, with trees serving as main food sources and for sleeping sites. Large portions of agricultural areas were also included in their home-ranges. ${ }^{51}$ Vervet monkeys are nonspecialist feeders adapted to strongly fluctuating resource availability. Their diet includes fruits, seeds, pods, flowers, leaves, buds, sap, gum, grasses, invertebrates, and occasionally vertebrates such as small 
reptiles, nestling birds and eggs. In the Kala Maloue National Park, Cameroon, a distinct seasonal change in the diet of Cercopithecus aethiops tantalus was observed by Nakagawa. ${ }^{52}$ According to Zinner et al. ${ }^{51}$ during the dry season more time is spent feeding on woody plants than on grasses, with slightly more time spent in grasslands during the wet season, common with vervet monkeys in the national park. Brennan et al. ${ }^{53}$ indicated that seasonality has a definite influence on the diet of vervet monkeys in a tourist-lodge habitat in Amboseli National Park, Kenya: where vervet monkeys around the lodge become more dependent on human foods during the dry seasons when fewer natural food sources are available, often leading to conflict with man.

Mona monkeys were the most observed in the lowland forest fragments and they mainly occupied the high canopy of the forest structure. They moved in grouped between 8 and 18 in the national park and were the second most encountered groups after putty-nosed monkeys. We observed mona monkey in the lowland forest during the rainy season and in the dry season, groups retreated to the gallery forests especially due to high human presence in the lowland forest fragments during the dry season. Food and fruits were noted to be more in the gallery forests during the dry season than in the degraded lowland forest. Mona monkeys have few food competitors in the national park (except the white-nosed monkey) were they jointly used both the lowland forests and the gallery forest areas. They are adapted to the present environmental conditions and are facing hunting pressure threats.

White-nosed monkeys were the most encountered primate species in the national park with a total of 13 groups. Their density was $1.3 /$ $\mathrm{km}^{2}$ with an encounter rate of $0.52 / \mathrm{km}$. They were mainly found in the gallery forest and lowland forest areas where there is abundant food supply. They were noted to inhabit the high canopy of the forest and only come to the floor when there is food availability. This is in line with Oates ${ }^{54}$ who stated putty-nosed monkeys were found to use mainly the vertical strata of the forest, with a clear preference for the upper forest canopy in the Tai National Park. Putty-nosed monkeys are relatively widespread in Cameroon and Nigeria, where they can be found in patches of high and gallery forests along rivers. ${ }^{54}$ Their main competitor in terms of food is the Mona monkeys which are also forest species. They are one of the most hunted species in the park and most importantly affected by the incidence of habitat fragmentation. They feed mainly on fruits especially landolphia and aframomom spp. They were mainly detected in very steep landscape areas of the gallery forests with seasonal streams and springs. ${ }^{55-57}$

\section{Conclusion}

Human activities in protected areas such as the Kimbi Fungom National Park have been at the helm of primates' distribution. Despite the significant presence of anthropogenic activities in the national park, the primate population is still high. Their number did not correlate with the forest fragment size. This is in fact a strong signal that primates in the park have adapted to the various fragment sizes. But the location and the structure of the forest fragments spoke well for the primate distribution. That is why habitat types, habitat structure and the landscape strongly influenced the primates in the national park. Our line transects method, supplemented with data on primate group size from interviews and focus group discussion, helped in the calculation of densities of the primate population in the park. These line transect surveys with many observers were very important in estimating the number of primate groups inhabiting a particular habitat type. Patas monkeys were observed foraging more on the lower vegetations of the savanna while white-nosed monkeys were observed utilizing the high canopy areas of the gallery forests. However, primates in this national park are facing anthropogenic challenges, mainly hunting pressure, hence there is need for a fortified primate conservation management plan to be established that would restrict poaching and encourage sustainable agriculture.

\section{Acknowledgments}

None.

\section{Conflicts of interest}

The authors declare that there is no conflict of interest regarding the publication of this article.

\section{References}

1. Brown JH, Mehlman DW, Stevens GC. Spatial variation in abundance. Ecology. 1995;76(7)2028-2043.

2. Chapman CA, Peres CA. Primate conservation in the new millennium: the role of scientists. Evolutionary Anthropology. 2001;10(1):16-33.

3. Peres CA. General guidelines for standardizing line-transect surveys of tropical forest primates. Neotropical Primates. 1999;7:11-16.

4. Pinto N, Lasky J, Bueno R, et al. Primate densities in the Atlantic Forest of Southeast Brazil: The role of habitat quality and anthropogenic disturbance. In: Garber PA, Estrada A, Bicca-Marques JC, et al. editors, South American primates: Comparative perspectives in the study of behavior, ecology, and conservation, New York: Springer; 2009:413431.

5. Bobadilla UL, Ferrari SF. Habitat use by Chiropotes satanas utahicki and syntopic Platyrrhines in Eastern Amazonia. American Journal of Primatology. 2000;50(3):215-224.

6. Wallace RB, Painter RLE, Taber AB. Primate diversity, habitat preferences, and population density estimates in Noel Kempff Mercado National Park, Santa Cruz Department, Bolivia. Am J Primatol. 1998;46(3):197-211.

7. Afolayan TA, Agbelusi EA. Impact of seasonal wildfire on Biodiversity. Biennial conference of Ecoson, Abeokuta: University of Agriculture; 1997.

8. Food Agriculture Organization. Global forest resources assessment 2010. Rome: FAO; 2010. 163 p.

9. McKinley DC, RyanMG, BirdseyRA, et al. A synthesis of current knowledge on forests and carbon storage in the United States. Ecol Appl. 2011;21(6):1902-1924.

10. Rylands AB, Mittermeier RA, Silva-Júnior JS. Neotropical primates: taxonomy and recently described species and subspecies. Int Zoo Year b. 2012;46(1):11-24.

11. Grelle CEV. Predicting extinction of mammals in the Brazilian Amazon. Oryx. 2005;39(3):347-350.

12. Benchimol M, Peres CA. Predicting primate local extinctions within "real $\square$ world" forest fragments: a pan $\square$ neotropical analysis. Am J Primatol. 2014;76(3):289-302.

13. IUCN 1996. $1996 \mathrm{IUCN}$ red list of threatened mammals.

14. Cowlishaw G, Dunbar R. Primate Conservation Biology. Chicago: University of Chicago Press; 2000.

15. UNDP. The integration of biodiversity into National environmental assessment procedures. National Case Studies, Cameroon: Produced for the Biodiversity Planning Support Programme; 2001. 
16. Blake Stephen. The Ecology of Forest Elephant Distribution and its Implications for Conservation. Ph.D thesis, University of Edinburgh; 2002

17. Ojima KA, Galvin BL. Global Impact of land-use change: to understand global change, natural scientists must consider the social context influencing human impact on environment. Biological Sciences. 1994;44(5):300-304

18. Cristóbal-Azkarate J, Arroyo-Rodríguez V. Diet and activity pattern of howler monkeys in Los Tuxtlas, Mexico: effects of habitat fragmentation and implications for con- servation. Am J Primatol. 2007;69(9):1013-1029.

19. Laurance WF, Lovejoy TE, Vasconcelos HL, et al. Ecosystem decay of amazonian forest fragments: a 22- year investigation. Conserv Biol. 2002;16(3):605-618.

20. Adler FR, Nuernberger B. Persistence in patchy irregular landscapes. Theoretical Population Biology. 1994;45(1):41-75.

21. Harcourt AH, Doherty DA. Species-area relationships of primates in tropical forest fragments: a global analysis. Journal of Applied Ecology. 2005;42(4):630-637.

22. González-Solís J, Guix JC, Mateos E, et al. Population density of primates in a large fragment of the Brazilian Atlantic Rainforest. Biodiversity and Conservation. 2001;10(8):1267-1282.

23. Chaves OM, Stoner KE, Arroyo-Rodríguez V. Differences in diet between spider monkey groups living in forest fragments and continuous forest in Lacandona, Mexico. Biotropica. 2012;44(1):105-113.

24. Dunn JC, Cristóbal $\square$ Azkarate J, Vea JJ. Differences in diet and activity pattern between two groups of Alouatta palliata associated with the availability of big trees and fruit of top food taxa. Am J Primatol. 2009;71(8):654-662.

25. Chaves OM, Stoner KE, Arroyo-Rodríguez V. Seasonal differences in activity patterns of Geoffroyi`s spider monkeys (Ateles geoffroyi) living in continuous and fragmented forests in southern Mexico. Int $J$ Primatol. 2011;32(4):960-973.

26. Irwin MT. Diademed sifaka (Propithecus diadema) ranging and habitat use in continuous and fragmented forest: higher density but lower viability in fragments? Biotropica. 2008;40(2):231-240.

27. Moore DL, Vigilant L. A population estimate of chimpanzees (pan troglodytes schweinfurthii) in the ugalla region using standard and spatially explicit genetic capture-recapture methods. Am J Primatol. 2014;76(4):335-346.

28. Hacker JE, Cowlishaw G, Williams PH. Patterns of African primate diversity and their evaluation for the selection of conservation areas. Biological Conservation. 1998;84(3):251-262.

29. Tata FT. The Kimbi-Fungom National Park; a situation report. Bamenda, Cameroon: Green works company Ltd; 2015.

30. BirdLife International. Species factsheet: Eucometis pencillata. 2010.

31. Buckland ST, Anderson DR, Burnham KP, et al. Introduction to distance sampling: Estimating abundance of biological populations. New York, USA: Oxford University Press; 2001.

32. Arnold K, Zuberbühler K. Meaningful call combinations in a nonhuman primate. Current Biology. 2008;18(5):202-203.

33. Ross C, Reeve N. Survey and census methods: population distribution and density. In: Setchell JM, Curtis JC, editors, Field and Laboratory Methods in Primatology, Cambridge, UK: Cambridge University Press; 2003:90-109.

34. Buckland ST, Anderson DR, Burnham KP, et al. Distance sampling, estimating abundance of biological populations. London: Chapman \& Hall; 1993.
35. Mittelbach GG, Schemske DW, Cornell HV, et al. (Evolution and the latitudinal diversity gradient: speciation, extinction and biogeography. Ecology Letters. 2007;10(4):315-331.

36. Wiens JJ, Donoghue MJ. Historical biogeography, ecology and species richness. Trends in Ecology and Evolution. 2004;19(12):639-644.

37. Wiens JJ, Ackerly DD, Allen AP, et al. Niche conservatism as an emerging principle in ecology and conservation biology. Ecology Letters. 2010;13(10):1310-1324.

38. Romdal TS, Araújo MB, Rahbek C. Life on a tropical planet: niche conservatism and the global diversity gradient. Global Ecology and Biogeography. 2013;22(3):344-350.

39. Vitousek PM, Mooney HA, Lubchenco J, et al. Human domination of Earth's ecosystems. Science. 1997;277(5325):494-499.

40. Mvo Denis Chuo, Tsi Evaristus Angwafo. Status of large mammals: case study of gorilla (Gorilla gorilla diehi), chimpanzee (Pan troglodytes ellioti) and buffalo (Syncerus caffer), Menchum South, NW Cameroon. International Journal of Environment, Agriculture and Biotechnology (IJEAB). 2016;2(4)

41. Ikemeh RA. Population Survey of Nigerian-Cameroon Chimpanzees (Pan troglodytes ellioti) in Southwestern Nigerian Priority Sites: Idanre Forest Cluster and Ise Forest Reserve. African Primates. 2013;8:39-50.

42. Nkwatoh Athanasius Fuashi, Akenji Lesly Nji, Melle Maurice Ekane, et al. Assessing the impact of seasonality on Cross River Gorilla Nest Construction at Kagwene Gorilla Sanctuary, North-West Cameroon. Journal of Ecology and the Natural Environment. 2017;9(11):177-184.

43. Agaldo JA, Gwom TG, Apeverga PT. Assessment of present threats and associated conservation implications to the Oban Division forest Cross river National Park, Nigeria Biodiversity hotspots. Ethiopian Journal of Environmental studies and management. 2016;9(suppl 2):938-950.

44. Morgan B, Adeleke A, Bassey T, et al. Regional action plan for the conservation of the Nigeria-Cameroon Chimpanzee (Pan troglodytes ellioti). CA, USA: IUCN/SSC Primate Specialist Group and Zoological Society of San Diego; 2011

45. Whiten A, Byrne RW, Barton RA, et al. Dietary and foraging strategies of baboons. Philos Trans R Soc Lond. 1991;334(1270):187-197.

46. Cawthon Lang KA. Primate Factsheets: Olive baboon (Papio anubis) Behavior. 2006

47. Van Doorn A. The interface between socioecology and management of chacma baboons (Papio ursinus) in the Cape Peninsula, South Africa. PhD thesis. Zoology Department; University of Cape Town; 2009.

48. Skelton S. Savanna Baboon (Papio cynocephalusd). 2007.

49. Isbell LA, Chism J. Distribution and Abundance of Patas Monkeys (Erythrocebus patas) in Laikipia, Kenya. Am J Primatol. 2007;69(11):1223-1235.

50. Dunbar R, Barrett L. Cousins our primate relatives. London: BBC Worldwide Ltd; 2000. ISBN-10: 0563551151.

51. Zinner D, Torkler F, Peláez, F. Distribution and habitat of hamadryas baboons (Papio h. hamadryas) in Eritrea. Int J Primatol. 2001;22(3):397-413.

52. Nakagawa N. Difference in food selection between patas monkeys (Erythrocebus patas) and tantalus monkeys (Cercopithecus aethiops tantalus) in Kala Maloue National Park, Cameroon, in relation to nutrient content. Primates. 2003;44(1):3-11.

53. Brennan EJ, Else JG, Altmann J. Ecology and behaviour of a pest primate: vervet monkeys in a tourist-lodge habitat. Afr $J$ Ecol. $1985 ; 23(1): 35-44$. 
54. Oates JF, Butynski TM. Mandrillus leucophaeus. In: IUCN 2008, IUCN red list of threatened species. 2008.

55. Almany GR. Differential effects of habitat complexity, predators and competitors on abundance of juvenile and adult coral reef fishes. Oecologia. 2004;141(1):105-113.
56. Martin RD, Soligo C, Tavaré S. Primate origins: implications of a cretaceous ancestry. Folia Primatologica. 2007;78(5-6):277-296.

57. Peres CA. Synergistic effects of subsistence hunting and habitat fragmentation on Amazonian forest vertebrates. Conservation Biology. 2001;15(6):1490-1505. 